\title{
Development of a New Device for Investigating Creep Force between Wheels and Rails
}

\author{
Hisayo DOI \\ Assistant Senior Researcher, \\ Takefumi MIYAMOTO, Dr. Eng. \\ Laboratory Head, \\ Vehicle Mechanics Laboratory, Railway Dynamics Division \\ Yukio NISHIYAMA \\ Manager, \\ Design \& Manufacture Department, Research \& Development Promotion Division \\ Shintaro OHE \\ Senior Researcher, \\ Traction Control Laboratory, Vehicle Control Technology Division \\ Hideya KAMACHI \\ JR Souken Information Systems Co., Ltd

\begin{abstract}
A new experimental device has been developed to investigate creep forces between wheels and rails. The device - called the Creep Tester - is applicable to existing rails, and its wheel is capable of rolling on rails while using a specific mechanism to alter any longitudinal creepage generated. The Creep Tester is also equipped with a mechanism for setting wheel yaw angles to induce lateral creepage. Along with a number of other features (including a short measuring time and the ability to set normal forces), the device is advantageous in ascertaining the parameters that affect creep force characteristics.
\end{abstract}

Keywords: creep force, creepage, coefficient of friction, measurement

\section{Introduction}

As understanding tangential creep forces between wheels and rails is an essential element in determining vehicle dynamics, many researchers have investigated the characteristics of creep forces using creep force/creepage curves in both theoretical and experimental studies [1 - 13].

Twin-disc (cylindrical) rolling contact machines or wheelsets equipped with roller rigs are usually applied to experimental studies [9 - 13] of creep forces between wheels and rails because they represent manageable ways to control the rolling speed of discs/roller rigs and slip (creepage) at contact points, which are factors that determine creep forces. Experiments with this kind of machinery, however, can be performed only in laboratories rather than on existing track rails. The surface condition of existing rails (which affects creep forces) varies widely with dry and lubricated status as well as contamination, but it is not easy to set a surface condition in laboratories that is equivalent to that of rails in the field. Moreover, there are differences between actual rails and the rollers of rolling contact machinery: the curvature of the rollers used as substitutes for rails is much larger than that of an actual rail top, and their profile will vary earlier than that of a rail during measuring operation since each rotation accelerates wear to the roller if the contact position is not changed during measurement. Some experiments have been carried out using full-scale cars on existing rails [14], but even here it was difficult to ascertain creep force adequately for a number of reasons: it is arduous to manage the setting of creepage from small to large values, and it is also difficult to detect the contact point between the wheel and rail, which is essential in ascertaining creepage accurately. The authors have therefore produced a new experimental device called the Creep Tester as shown in Fig. 1. The device measures creep force and creepage between its testing wheel and existing rails. One of its features is a mechanism that can alter longitudinal creepage while the testing wheel is rolling. It is also capable of inducing lateral creepage to generate lateral creep force in the direction of flange climb derailment. In addition, it can be used to create a creep force/creepage curve through a single measurement operation within less than ten seconds.

This paper reports on the device's mechanism and the results of some fundamental experiments using it under dry and lubricated conditions.

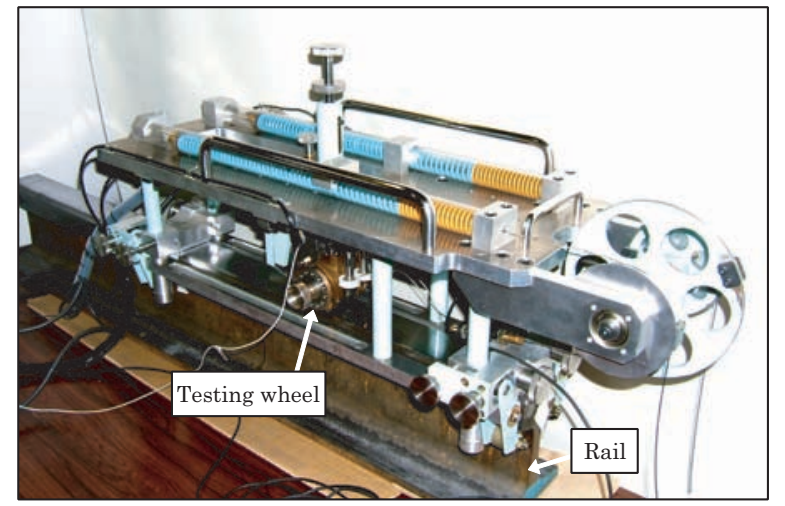

Fig. 1 Overall view of the Creep Tester set on a rail 
Table 1 Creep Tester specifications

\begin{tabular}{|l|l|}
\hline \multirow{2}{*}{ Size } & $\begin{array}{l}\text { Length: } 780 \mathrm{~mm} \\
\text { Width: } 230 \mathrm{~mm}\end{array}$ \\
& Height: $360 \mathrm{~mm}$ \\
\hline Mass & $26 \mathrm{~kg}$ \\
\hline Testing wheel & $\begin{array}{l}\text { Diameter: } 60 \mathrm{~mm} \\
\text { (standard) }\end{array}$ \\
\hline Drum diameter & Material: C105U (ISO) with quench hardening \\
\hline Settings of truck velocity $V_{t}$ & 40 mm \\
\hline Settings of normal force $N$ & $10,20,30,40,50 \mathrm{~mm} / \mathrm{s}$ \\
\hline Longitudinal spring force $F_{s}$ & 30 to $300 \mathrm{~N}$ \\
\hline Settings of testing wheel yaw angle $\psi_{w}$ & $0,0.3,0.6,1.0$ degrees \\
\hline Rotary encoder resolution & $\begin{array}{l}\text { Testing wheel: } 3,600 \text { pulses/rotation } \\
\text { Truck: } 400 \text { pulses/rotation }\end{array}$ \\
\hline Ball screw pitch & 2 mm/rotation \\
\hline
\end{tabular}

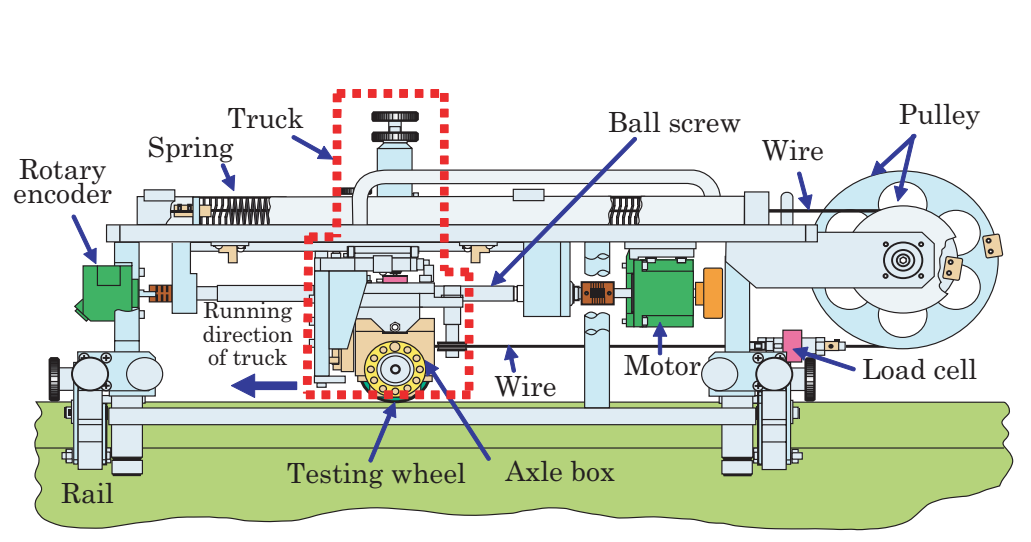

(a) Side view

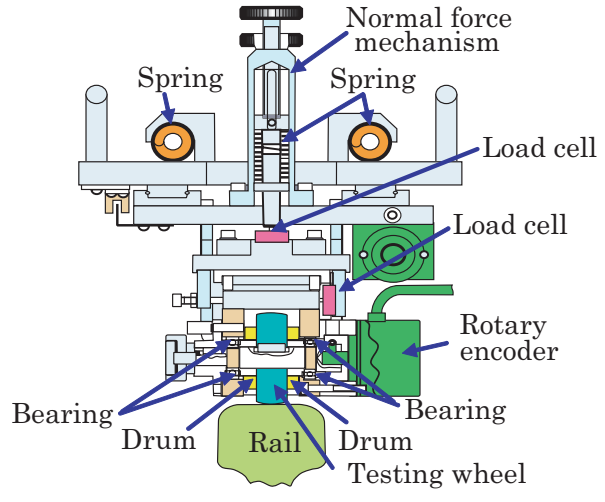

(b) Sectional view

Fig. 2 Schematic diagram of the Creep Tester

\section{Mechanism of the Creep Tester}

Figure 1 shows the Creep Tester placed on an actual rail (the Japanese $50 \mathrm{~N}$ type) with a length of $1 \mathrm{~m}$, and Table 1 indicates its specifications. As the table shows, the Creep Tester is a portable device equipped with handles, and has a mass of approximately $26 \mathrm{~kg}$ and a maximum length of $780 \mathrm{~mm}$. In order to investigate creep force characteristics, the device measures the following experimental values simultaneously: longitudinal creep force $F_{x}$, lateral creep force $F_{y}$, normal force $N$, its own testing wheel velocity $V_{w}$, and the velocity $V_{t}$ of the truck carrying it. These forces are measured using strain load cells located as shown in Fig. 2, and the velocities are evaluated through a velocity operating system using pulses from two rotary encoders. One of these encoders is set to the testing wheel's axle, and the other is set to the end of a ball screw shaft. The Creep Tester's truck, which consists of a normal force mechanism, an axle box and testing wheels, is connected to the ball screw. An electric motor placed at the end of the ball screw shaft drives the truck in the longitudinal direction.

\subsection{Longitudinal creep force mechanism}

One of the Creep Tester's distinguishing features is a mechanism that creates longitudinal creep force for a broad range of creepage with a single measurement procedure. A simplified diagram of this mechanism is shown in Fig. 3. As illustrated in Fig. 2 and Fig. 3, the longitudinal creep force mechanism consists of springs, drums attached to the testing wheel, wires and pulleys. The Creep Tester's measurement procedure and the action of the longitudinal creep force mechanism are outlined below.

At first, the yaw (attack) angle of the testing wheel is set to induce lateral creepage, and a normal load between the testing wheel and the rail is then applied using the normal force mechanism as shown in Fig. 2 (b). After this setting, the motor drives the truck using the ball screw, and the testing wheel starts rolling together with the truck on the rail. At the beginning of rolling, the testing wheel rolls freely with little slip since almost no force is applied by the springs of the longitudinal creep force mechanism. As the testing wheel rolls forward, the wires of the mechanism are wound around the drums attached to the testing wheel's rim, and pull the springs of the 
mechanism in the longitudinal direction. This action increases the spring force $F_{s}$ gradually in proportion to the length of the wire wound around the drums. Using $r_{w}$ as the testing wheel radius and $r d$ as the drum radius, the longitudinal creep force $F_{x}$ exerted on the contact surface between the testing wheel and the rail can be described as $F_{x}=\left(r_{d} / r_{w}\right) F_{s}$. This means that the longitudinal creep force mechanism increases the longitudinal creep force between the testing wheel and the rail. Simultaneously, the action of the mechanism also increases the longitudinal creepage by degrees due to the difference between the two velocities of the testing wheel and the truck, since the spring force acts to disturb the rolling of the testing wheel. As a result, the velocity of the testing wheel is reduced gradually. At the last moment of the measurement, the spring force becomes so strong that the testing wheel is unable to keep rolling, and finally begins to slide on the rail. At that moment, an external signal stops the driving of the truck. The Creep Tester executes a single measurement within a few seconds, and can obtain data on longitudinal and lateral creep forces for a broad range of longitudinal creepage.

As described above, the Creep Tester is able to generate lateral creepage by adding a yaw angle. The axle box of the Creep Tester can be turned about the normal axis in order to apply a yaw angle to the testing wheel against the rail. During measurement, the yaw angle is fixed, and four yaw angle settings can be assigned as shown in Table 1. The Creep Tester, consisting of a longitudinal creep force mechanism and yaw angle apparatus, is able to measure longitudinal and lateral creep forces simultaneously to enable investigation of the relationship between them.

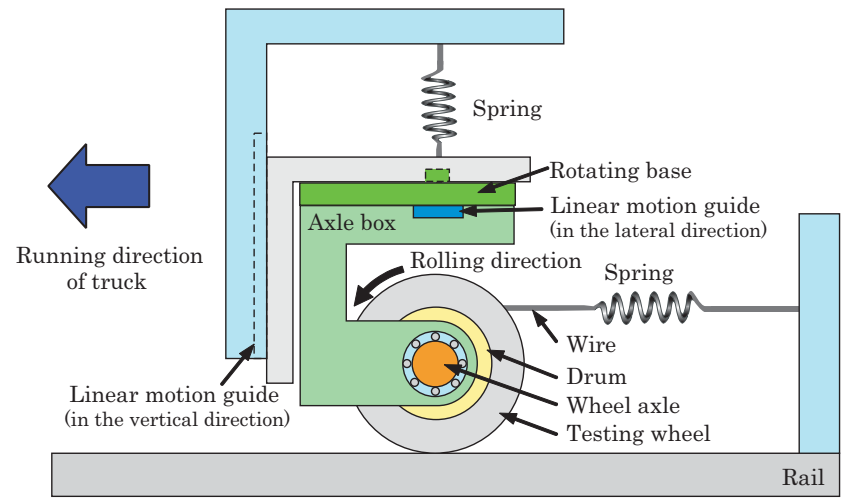

Fig. 3 Longitudinal creep force mechanism of the Creep Tester

\subsection{Measurement of velocity and creepage}

In the investigation of creep force characteristics, it is essential to accurately ascertain creepage, especially for small creepage values. Using $s_{x}$ as the longitudinal creepage, $V_{w}$ as the testing wheel velocity and $V_{t}$ as the truck velocity, $s_{x}$ is given by $s_{x}=2\left(V_{t}-V_{w}\right) /\left(V_{t}+V_{w}\right)$ when the yaw angle is zero. Thus, it is necessary to measure the small difference between the velocities $V_{t}-V_{w}$ in order to detect very small values of creepage. The Creep Tester measures velocities using a sort of pulse comparator consisting of a high-frequency base clock with a fre- quency of $20 \mathrm{MHz}$ and a counter.

When the Creep Tester's motor starts to drive the truck and the testing wheel, two of the rotary encoders generate pulse signals according to the rotation of the ball screw or the wheel axle. The distances of the testing wheel rotation and the truck movement corresponding to the pulses are evaluated by a number of parameters as indicated in Table 1 - the rotary encoder resolution, the ball screw pitch and the diameter of the testing wheel. Therefore, the only remaining parameter needed to ascertain each of the velocities is the time corresponding to the pulses. The timing of the pulses from the encoder can be measured by counting the number of pulses of the high-frequency $(20 \mathrm{MHz})$ base clock included in one pulse of the encoder. The accuracy of velocity measurement depends on the setting speed of the truck. For a speed of $10 \mathrm{~mm} / \mathrm{s}$, it can be determined with an error of $\pm 0.002 \%$. By applying this system, very small creepage values can be ascertained with high accuracy from the velocities.

\subsection{Normal force mechanism}

The normal force mechanism is a type of apparatus that loads a normal force between the testing wheel and the rail (Fig. 2 (b)). The normal force is modifiable up to $300 \mathrm{~N}$ by using a spring as referred to in Table 1 to simulate the maximum Hertzian pressure between the wheel and rail generated in actual operation service.

The measured value of the normal force is given by the total value of the weight of part of the truck and the force measured by a load cell placed as shown in Fig. 2 (b).

\subsection{Testing wheel}

The basic-specification testing wheel has a spherical surface with a radius of $30 \mathrm{~mm}$, and is quench-hardened (Table 1) to reduce wear stemming from rolling contact. The standard surface roughness (the arithmetic mean roughness $R_{a}$ ) of the testing wheel is approximately 0.3 $\mu \mathrm{m}$.

The testing wheel of the Creep Tester is replaceable, enabling models with various profiles, materials and levels of surface roughness etc. to be used according to the intended purpose of the experiment.

\section{System configuration of the Creep Tester}

A system specialized for the Creep Tester is used to control and monitor the device and collect measurement data; Fig. 4 shows the system configuration. The Creep Tester executes measurement of creep force characteristics according to the flow of control, monitoring and measurement data outlined in the figure.

\subsection{Pulse-counting unit and stage controller}

The pulse-counting unit is an element with a highfrequency base clock and a counter, as described in Section 2.2. By counting the base clock's pulses correspond- 


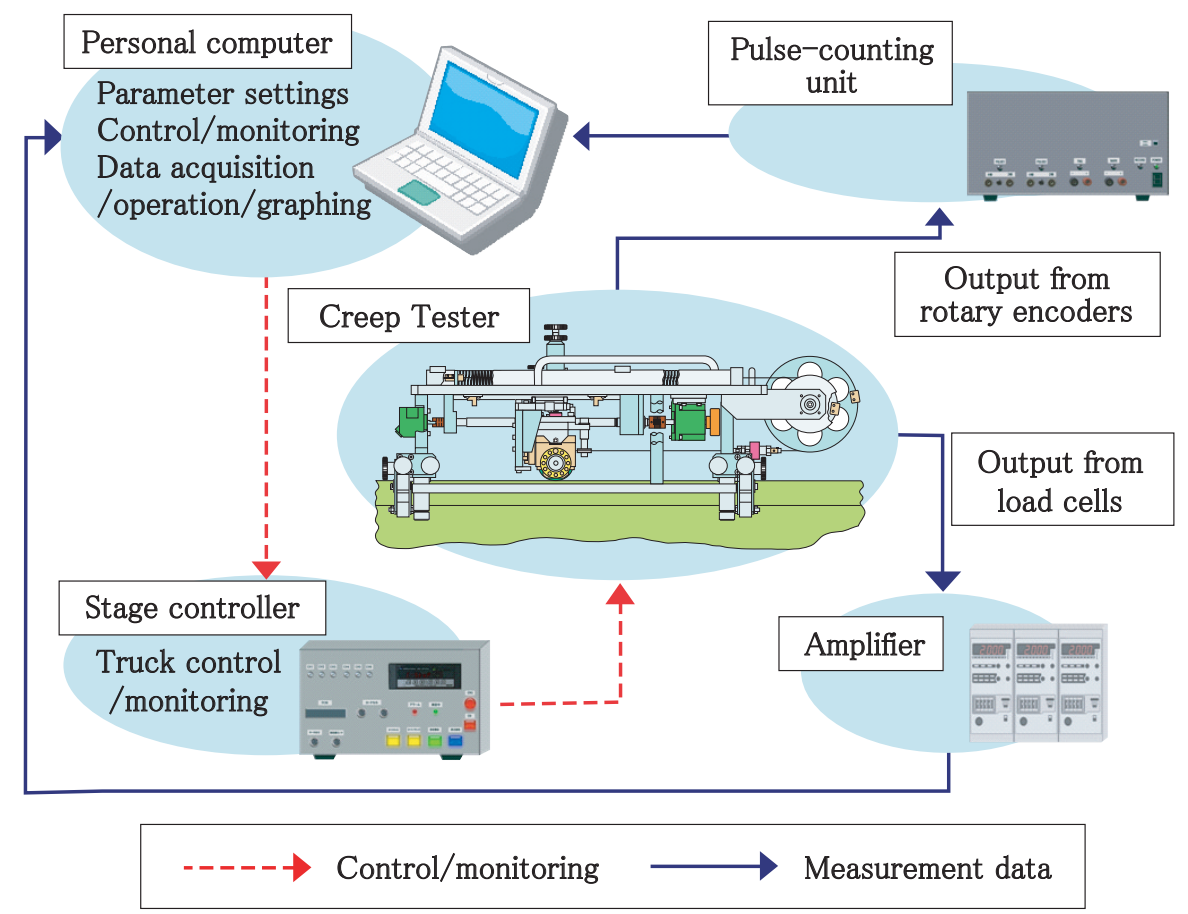

Fig. 4 System configuration

ing to pulses from the rotary encoder attached to the testing wheel or the ball screw of the truck, the pulsecounting unit measures the time taken to cover a constant distance around/along the testing wheel/ball screw. A personal computer (PC) with software developed for the Creep Tester collects the counted values from the pulse-counting unit and calculates the velocities of the testing wheel and truck using the parameters of the wheel radius and the ball screw pitch.

The stage controller controls the motor driving the truck under orders from the PC. It also monitors the truck position and the motor condition. Emergency shutdown can be performed and the truck can be returned to the measurement starting position by directly operating the stage controller.

\subsection{Software and measurement data graphing}

A Windows PC program is used to control and monitor the system of the Creep Tester and collect measure-

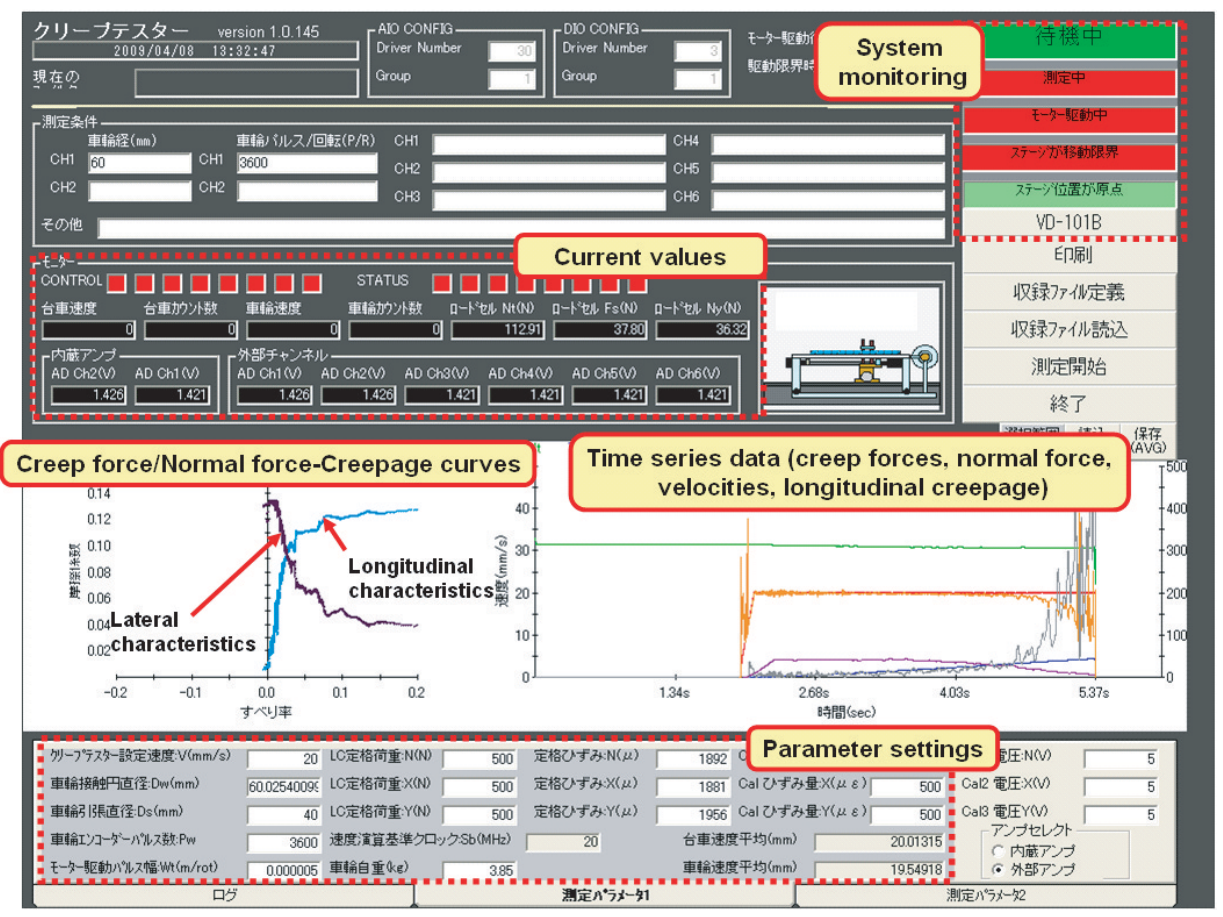

Fig. 5 Graphical user interface (in Japanese) 
ment data. It also calculates the longitudinal creepage and the velocities of the testing wheel and the truck, and ascertains physical quantities from voltage data using a number of parameters.

Figure 5 shows the program's graphical user interface (GUI in Japanese). Through this GUI, users input parameters to be used for calculating velocity/force/creepage. The interface also shows the condition of the system and the current values of physical quantities. Additionally, after collecting data and implementing a number of calculations, the software indicates the results of measurement in graph form. The right-side graph in Fig. 5 shows measurement data in time-series analysis. Dragging the cursor over the graph allows the user to select a certain time range to derive creep force characteristics, and creep force/creepage curves are drawn in the left-side graph corresponding to the data selected. This function enables users to check creep force characteristics immediately in the field. The program also has a function to output data files in ASCII format.

\section{Fundamental experiments with the Creep Tester}

\subsection{Experimental overview}

Some fundamental experiments were executed using the Creep Tester with the testing wheel as shown in Table 1. First, the correlation between the device's measurement action and measurement data in time-series representations was examined. Second, experiments were performed for assessment of its basic ability to detect different friction coefficient conditions (dry or lubricated) on rails. Further experiments were also carried out to investigate the effects of lateral creepage induced by the yaw angles of the testing wheel (with settings of 0.3 and 0.6 degrees) on longitudinal and lateral creep forces.

In these experiments, several parameters that affect creep forces were set to be identical as outlined below.

The rail used for the experiments had a flat surface to avoid complicated contact conditions arising from various rail profiles. The surface of the rail was polished with \#80 abrasive paper in the longitudinal direction. Through this polishing, the surface roughness, $R_{a}$, of the rail was set at approximately $0.2 \mu \mathrm{m}$ in the longitudinal direction and $0.5 \mu \mathrm{m}$ in the lateral direction. The contact plane between the testing wheel and the rail consisted of a circular area since the surface of the rail was flat and that of the testing wheel was spherical. The normal force applied by the normal force mechanism was set at $200 \mathrm{~N}$, providing a Hertzian pressure of approximately $820 \mathrm{MPa}$. The value of the Hertzian pressure was almost equal to that generated between the tread of a wheel with a Japanese modified arc profile and the top surface of a rail with the Japanese $50 \mathrm{~N}$ rail profile in contact under a vertical load of approximately $40 \mathrm{kN}$. The lubricated condition was set by spreading a sort of grease used in service over the flat surface of the rail. The truck's setting speed was $20 \mathrm{~mm} /$ $\mathrm{s}$. All the experiments were implemented in a laboratory.

\subsection{Creep Tester measurement action and data in a time sequence}

Figure 6 (a) shows data in a time sequence obtained from measuring operation using the Creep Tester with a yaw angle $\psi_{w}$ of 0.6 degrees. It indicates the data until the point at which the testing wheel began to slide on the rail. In the figure, $F_{x}$ and $F_{y}$ respectively represent the longitudinal and lateral components of the creep force.

In Fig. 6 (a), it can be seen how the longitudinal creep force mechanism generates longitudinal creep force, testing wheel velocity $V_{w}$ and longitudinal creepage $s_{x}$. Almost no longitudinal creep force is induced at the beginning of measurement, but the value increases by degrees with the passage of time. The testing wheel rolls with almost the same velocity as the truck at the beginning of rolling. As the longitudinal creep force rises, the wheel's velocity becomes slightly less than that of the truck. Consequently, longitudinal creepage increases significantly in line with the decline of the testing wheel's velocity.

Lateral creep force in the initial moment was not measured because, in preparation for measurement, the axle box was arranged so as not to be in contact with the load cell detecting the lateral creep force. When the testing wheel started rolling, the yaw angle induced lateral creepage and lateral creep force naturally. The yaw angle was set to a sufficiently large value to cause significant lateral creepage, so the lateral creep force increased rapidly. After reaching its maximum value, this force started to decrease gradually. Figure 6 (a) also shows that the

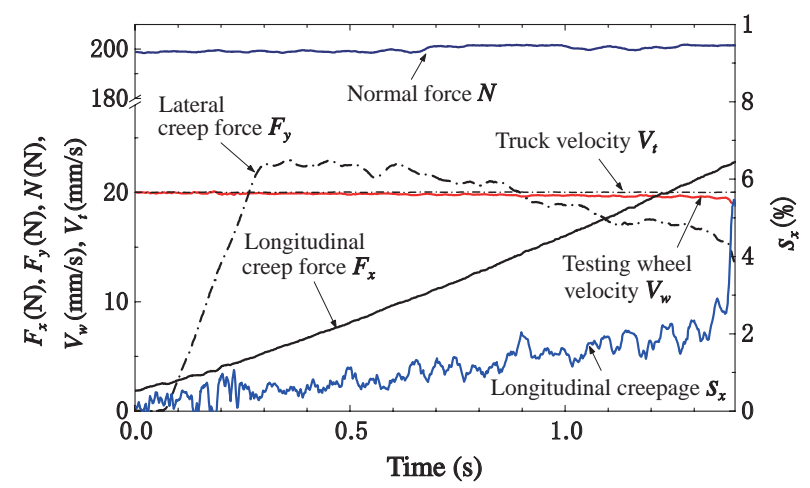

(a) Time-series data

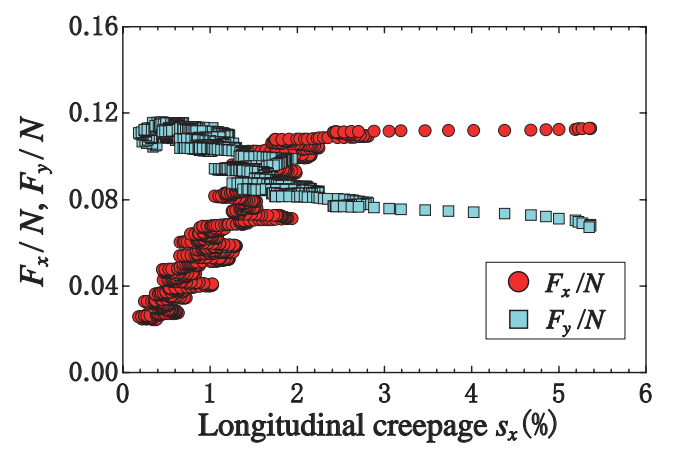

(b) Creep force curve for selected data from Fig. 6 (a)

Fig. 6 Example of data obtained from a single measurement by the Creep Tester

(Rail surface with grease; yaw angle: 0.6 degrees) 
normal force, $N$, maintained an almost constant value during the measurement.

The creep force/creepage curves derived from selected data in Fig. 6(a) of the time after the lateral creep force reaching its maximum value resulted in Fig. 6 (b). Figure 6(b) shows the ratios of the longitudinal and lateral creep force to the normal force, $F_{x} / N$ and $F_{y} / N$, against the longitudinal creepage, $s_{x}$. The longitudinal creep force ratio, $F_{x} / N$, increases to some extent in line with the longitudinal creepage increase. On the other hand, the lateral creep force ratio, $F_{y} / N$, decreases in line with the increase in longitudinal creepage. During measurement, the lateral creepage scarcely varied because of the fixed yaw angle. Accordingly, the results indicate that longitudinal creepage influences not only longitudinal creep force but also lateral creep force. It is conceivable that the sharing ratio between longitudinal and lateral creepage on the contact area determines the correlation between the magnitude of the longitudinal and lateral creep forces where the saturation values of both creep force ratios, $F_{x} / N$ and $F_{y} / N$, are almost identical.

\subsection{Creep force characteristics under lubricated and dry conditions}

Figure 7 shows the results of experiments conducted under lubricated and dry conditions with a yaw angle of zero. $F_{y}$ did not occur because no lateral creepage was induced. In order to ensure the reproducibility of the measurements, we carried out the experiments 20 times under each condition. The data shown in Fig. 7 are those of 20 measurements averaged by a certain method.

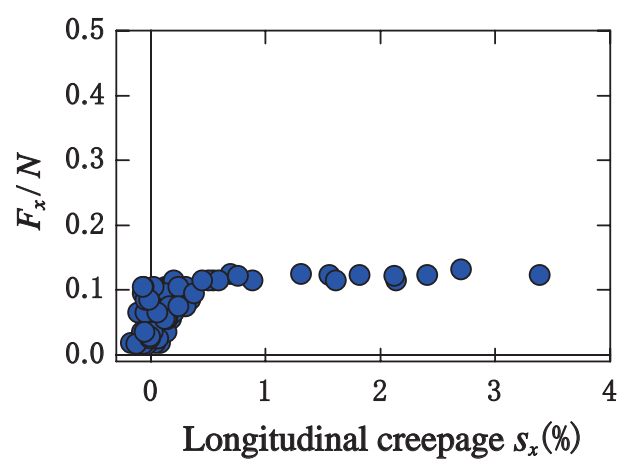

(a) Rail surface with grease

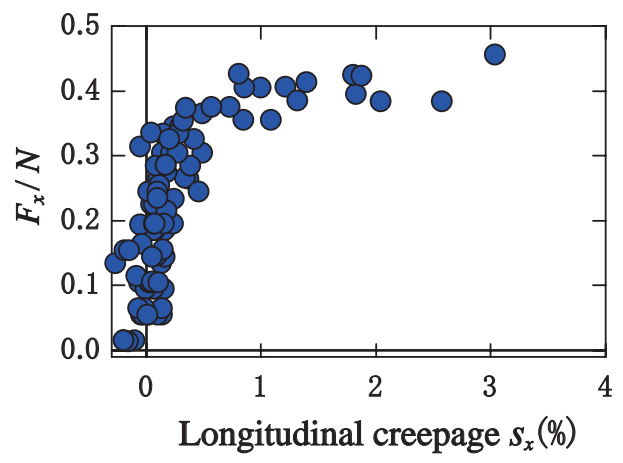

(b) Dry conditions

Fig. 7 Comparison between a greased rail and dry conditions (no yaw angle)
Both ratios of longitudinal creep force to normal force (as shown in Fig. 7 (a) and Fig. 7 (b)) have almost the same tendency of rapid increase that is nearly in proportion to the creepage when its value is very small. When the creepage becomes larger, each of the ratios saturates at a certain value. The saturation value of $F_{x} / N$ under lubricated conditions is approximately 0.12 , and that under dry conditions is around 0.4 . The saturation values of $F_{x} / N$ under the two conditions are clearly different from each other. Thus, Fig. 7 indicates that the Creep Tester is capable of investigating contamination effects on creep forces.

\subsection{Effects of yaw angle on creep forces}

Figure 8 shows average data from 20 measurements with yaw angles 0.3 degrees and 0.6 degrees where the rail surface was lubricated with grease.

In Fig. 7, the data in larger creepage under dry conditions (Fig. 7 (b)) show a wider spread than those under lubricated conditions (Fig. 7 (a)). Some parameters, such as the temperatures of the contact surfaces, atmospheric temperature and humidity etc., most likely affect creep forces as referred to in [15] and [16]. During the 20 measurements, such parameters were unstable, and are thought to have affected creep forces more directly under dry conditions than in the case of lubrication. Figure 8 therefore shows data obtained from mea-

\begin{tabular}{|ccc|}
\hline Creep Tester & $\bigcirc F_{x} / N, \square \quad F_{y} / N$ \\
& $\star \quad F / N=\sqrt{F_{x}^{2}+F_{y}^{2}} / N$ \\
FASTSIM & & $F_{x} / N,-\cdot-F_{y} / N$ \\
\cline { 2 - 3 } & &
\end{tabular}

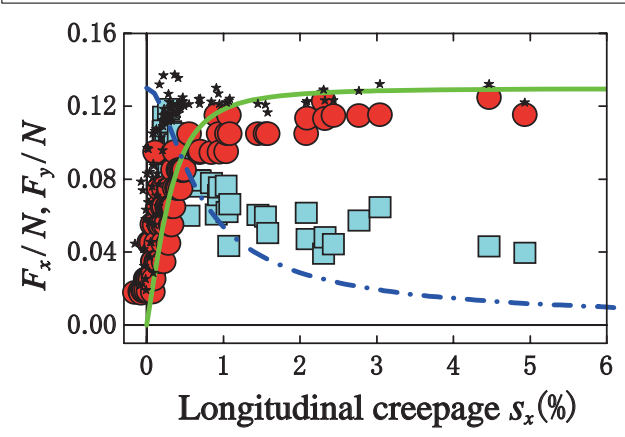

(a) Yaw angle: 0.3 degrees

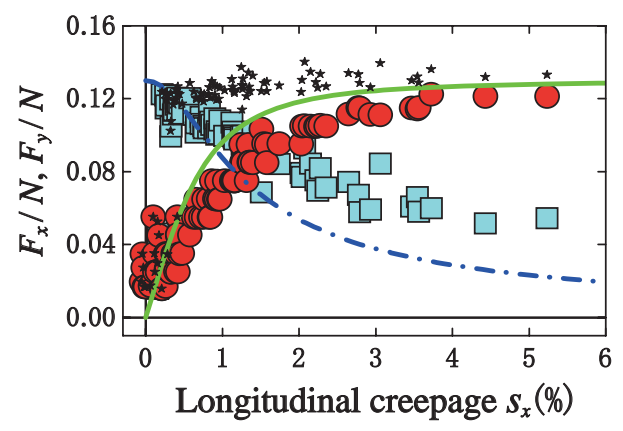

(b) Yaw angle: 0.6 degrees

Fig. 8 Effects of yaw angle on creep forces, and comparison with theoretical values by FASTSIM (Rail surface with grease) 
surements under more stable conditions. The results obtained by the Creep Tester as shown in Fig. 8 indicate that the initial slope of $F_{x} / N$ at a yaw angle of 0.3 degrees is significantly different from that at a yaw angle of 0.6 degrees. The initial slope with the larger yaw angle is less inclined than that with the smaller angle, although the ratios of the absolute creep forces against normal force, $F / N$, for both yaw angles reach almost the same saturated value of approximately 0.13 when the longitudinal creepage $s_{x}$ is sufficiently increased. The larger yaw angle induces larger lateral creepage, so the initial slope of $F_{x} / N$ is less inclined with a yaw angle of 0.6 degrees compared to one of 0.3 degrees. Figure 8 also illustrates the relationship between longitudinal creep forces and lateral ones. It indicates that $F_{y} / N$ decreases in line with increasing longitudinal creepage, while $F_{x} /$ $N$ increases. Due to the larger lateral creepage, $F_{y} / N$ in Fig. 8 (b) decreases more slowly than that in Fig. 8 (a).

Theoretical curves calculated using Kalker's FASTSIM algorithm [6] are also plotted as solid or dotted lines in Fig. 8, where the friction coefficient adopted in the calculation was set at 0.13 . Lateral creepage $s_{y}$ is expressed as $s_{y}=V_{w} \sin \psi_{w} / V_{\text {mean }}$, where $V_{\text {mean }}=\left(V_{w} \cos \psi_{w}+\right.$ $\left.V_{t}\right) / 2$, and $\psi_{w}$ is the yaw angle. However, the lateral creepage $s_{y}$ applied here to FASTSIM was assumed to be a constant value determined by $s_{y}=\sin \psi_{w}$ for convenience. The lateral creepage applied to FASTSIM was therefore approximately $0.5 \%$ for a yaw angle of 0.3 degrees. For the other yaw angle of 0.6 degrees, lateral creepage was evaluated as about $1 \%$.

The conditions of some measurements obtained using the Creep Tester varied from those assumed for the hypothesis of FASTSIM as follows: FASTSIM deals with steady rolling contact, but the measurements made by the Creep Tester were executed under accelerating rolling conditions. Furthermore, the experimental contact surface with grease was under hydrodynamic lubrication conditions, but FASTSIM does not consider the shear stress of grease. Although some of the presuppositions involved are different as described here, Fig. 8 indicates that the respective tendencies of the experimental and theoretical values are relatively similar.

\section{Conclusions}

The Creep Tester is advantageous in investigating creep force characteristics in several ways: it is applicable to existing rails; creep force/creepage curves can be easily obtained within a short space of time; yaw angles or normal force can be set, etc. Considering these aspects, the Creep Tester is suitable for evaluating the effects of not only liquid lubricants but also those of solid (powdered) lubricants/sand/friction modifiers, which are difficult to apply to the rollers of rolling contact machinery. It is also capable of estimating the parameters that influence lateral creep force, which causes derailment.

The authors plan to conduct further investigations using the Creep Tester to comprehend creep forces under various conditions related to surface roughness, types of lubrication and friction modifiers, testing wheel profiles, contact pressure, etc. In addition, plans are also under way to measure the friction coefficient between a steel wheel and a concrete plane for application to vehicle running simulations to analyze the running behavior of vehicles on concrete slabs after derailment.

\section{References}

[1] Johnson, K. L., "The Effect of a Tangential Contact Force Upon the Rolling Motion of an Elastic Sphere on a Plane," Trans. ASME, J. Appl. Mech., Vol. 25, pp. 339-346, 1958.

[2] Vermeulen, P. J. and Johnson, K. L., "Contact of Nonspherical Elastic Bodies Transmitting Tangential Forces," J. Appl. Mech., Vol. 31, pp. 338-340, 1964.

[3] Johnson, K. L., Contact Mechanics, Cambridge University Press, Cambridge, 1985.

[4] Kalker, J. J., "Survey of Wheel-Rail Rolling Contact Theory,"Vehicle System Dynamics, Vol. 8, pp. 317-358, 1979.

[5] Kalker, J. J., Three Dimensional Elastic Bodies in Rolling Contact, $1^{\text {st }}$ ed., Kluwer Academic Publishers, Dordrecht, 1990.

[6] Kalker, J. J., "A Fast Algorithm for the Simplified Theory of Rolling Contact," Vehicle System Dynamics, Vol. 11, pp. 1-13, 1982.

[7] Iwnicki, S., Handbook of Railway Vehicle Dynamics, CRC Press, North Wales, pp. 85-141, 2006.

[8] Polach, O., "Creep forces in simulations of traction vehicles running on adhesion limit," Wear, Vol. 258, pp. 992-1,000, 2005.

[9] Oyama, T., "Fundamental Adhesion Phenomena between Wheel and Rail at Higher Speeds," Quarterly Report of RTRI, Vol. 26 (4), pp. 134-140, 1985.

[10]Oyama, T., "Some Basic Studies on the Influence of Surface Contamination on Adhesion Force between Wheel and Rail at High Speeds," Quarterly Report of RTRI, Vol. 30 (3), pp. 127-135, 1989.

[11]Zhang, W., Chen, J., Wu, X., and Jin, X., "Wheel/rail adhesion and analysis by using full scale roller rig," Wear, Vol. 253, pp. 82-88, 2002.

[12]Doi, H., Miyamoto, T., Maebashi, E., and Ishida, H., "Experimental Investigation of Creep Force Characteristics between Full-scale Wheel and Rail," JSME, Proc. the $11^{\text {th }}$ Transportation and Logistics Conference, pp. 447-450, 2002 (in Japanese).

[13]Ishida, H., Miyamoto, T., Maebashi, E., Doi, H., Iida, K. and Furukawa, A., "Safety Assessment for Flange Climb Derailment of Trains Running at Low Speeds on Sharp Curves," Quarterly Report of RTRI, Vol. 47 (2), pp. 65-71, 2006.

[14]Nagase, K., "An Investigation into the State of the Adhesion between Rails and Wheels by Slipping Adhesion Test Track," Quarterly Report of RTRI, Vol. 29 (2), pp. 80-85, 1988.

[15]Hou, K. and Kalousek, J., "Thermal Effect on Adhesion in Wheel/Rail Interface," Proc. CM2000, pp. 239$244,2000$.

[16]Ertz, M., and Bucher, F., "Improved Creep Force Model for Wheel/Rail Contact Considering Roughness and Temperature," Vehicle System Dynamics Supplement, Vol. 37, pp. 314-325, 2002. 